\title{
Community Mediation - Choosing a Direction
}

\section{Tricia Hayes}

\section{Abstract}

This article offers an exploration of the trajectory of the mediation movement both in the USA and in Ireland and contrasts this to the role envisioned for community mediation by activists in 70s USA. There is some discussion of the historical foundation of the community mediation movement, including the seeming erosion of core values inherent in the philosophical foundations of community mediation. The article concludes with an exploration of future implications and possibilities for the practice of community mediation.

\section{Introduction}

In their second publication of the 'The Mediators Handbook', Beer \& Steif (1997) make an interesting observation in the preface. They indicate their amazement at the growth of mediation in the USA between 1982 and 1997, from a little-known concept developed by community activists and others to a profession in its own right, widely taught and applied as a unique conflict resolution process.

Arguably, the same phenomenon has occurred in Ireland in the last 20 years. Mediation, a relatively unknown concept in early-nineties Ireland, is now established as a professional discipline in the area of conflict resolution. Mediation is promoted as an efficient and less costly method for resolving disputes in marital relationships, workplace relationships, business relationships, victim-offender relationships to name but a few (MII Website, 2017).

The direction the mediation movement has taken in Ireland follows that taken in the USA which is, essentially, to categorise disputes into a range of 'specialities' or 'relationship' types (Mediate.com website, 2017). This direction leaves the practice of community mediation in Ireland in somewhat of a dilemma. The title of an article by Charkoudian \& Billick (2015:233) "State of Knowledge: Community Mediation at a Crossroads", suggests that community mediation services in the USA find themselves in a similar position. 


\section{Content expertise or process skills?}

In exploring the dilemma from an Irish perspective, there is a question that immediately emerges as important for community mediation practice. Namely: given certain 'specialities' are already defined, what speciality might apply to community mediation practice?

In order to consider this question, it is helpful to discuss the philosophical foundation and core values underpinning community mediation as well as the literature discourse on the rise and development of the mediation method in general.

The philosophical foundation of community mediation has received attention from sociology scholars. For example, Harrington \& Merry (1988) discuss the philosophy in terms of meaningful human connection, moral growth and, ultimately, societal transformation. Coy \& Hedeen (2005) discuss the vision behind the emergence of community mediation in 70s USA.

The core values of consensus, empowerment, self-determination were seen as pivotal to the mediation process. Mediators would empower disputants to take ownership of their own disputes and disputants would learn about themselves and others in the process (Morrill \& McKee, 1993). This alternative system would keep many disputants from even seeing the inside of a courthouse. Coy \& Hedeen (2005) conclude, however, that in 2005 the vast majority of community mediation cases were court referrals. The quote by Eileen Steif "We haven't created an alternative to the court ... we've become an alternative to the courtroom" holds particular resonance here (Beer, 1986, p275).

In a telling article on the direction of community mediation in the USA, Charkoudian \& Billick (2015) present current challenges facing American community mediation services. One of the main challenges cited is the need to retain core values as services become increasingly institutionalised through lack of funding. They go on to argue that little or no evidence appears in the literature on how community mediation is meeting the traditional core values espoused by the movement. Forty years on, they present stark data concerning public knowledge of community mediation in the USA and conclude that "the vast majority of centers recognise that community members do not necessarily understand mediation or how to access services" (Charkoudian \& Billick (2015:258).

Much of the mediation literature discourse on the rise and development of mediation typically relates to what has made or what will make it an effective method of dispute resolution (Herrman et al, 2002). Although there are challenges to the limiting nature of this discourse in that it seems to reduce mediation to a simple settlement based or solution-focused process, the debate continues as to its potential (Pinzon, 1996; Bush \& Folger, 2005; Charcoudian \& Billick, 2015). 
One of the earliest key assertions leading to the current trajectory of mediation was that mediator 'process skills' alone would not be sufficient to successfully resolve disputes (Folberg \& Taylor, 1984; Moore, 1996; Susskind, 2000). The implicit assumption here was that the third party role of mediator would need to focus on the substance of the dispute. This approach closely resembled existing third party roles in formal dispute resolution methods such as litigation, arbitration and adjudication. These roles typically comprise one practitioner with a high level of knowledge on legislative and other formal processes relative to the dispute type. In the absence of any meaningful challenge in the literature to this assumption, it is no surprise that mediation specialities subsequently emerged or, indeed, that they mirror dispute areas that have a specific legislative context. It is also no surprise that, given the initial involvement of the American Arbitration Association in mediation training and education, the mediation movement has taken this direction (Folberg \& Taylor, 1984). Contrast this direction with that originally envisioned for community mediation and the move away from its philosophical foundation becomes obvious.

The core values of community mediation such as self-determination, voluntary participation, consensus, empowerment, impartiality and so on are widely accepted in the literature as underpinning all forms of mediation practice (Beer \& Steif, 1997; Bush \& Folger, 2005; Gazley et al, 2010). These core values have their roots in 'collective deliberation', a practice that can be traced back to ancient collaborative processes aimed at restoring harmony in times of discord long before the concept of mediation emerged. It is argued that often whole communities came together to take ownership of the restoration of harmony, all with the encouragement and support of rulers (Aureli \& De Waal, 2000; Strasser \& Randolph, 2004). In community mediation practice, the traditional feature of multiple mediators symbolises or honours the practice of collective deliberation. The mediators create an environment that nurtures reconciliation and human connection which, in turn, fosters resilience and moral growth (Hanaway, 2012).

Despite the clear philosophical foundation underlying the use of multiple mediators in community mediation practice, the literature discourse is focused on a different direction (Hanaway, 2012). In the main, the use of multiple mediators is reduced to a tactic, a strategy to enhance problemsolving as long as its use is justified (Hayes, 2006). These differing interpretations on the nature of the mediator as a third party reflect differing fundamental beliefs on the nature of conflict itself and the function of a third party. They also serve as the most obvious manifestation of this deep divide among mediation thinkers and practitioners. There is a certain irony in the fact that such a divide continues to flourish - given the self-professed raison d'etre of the mediation fraternity itself. 


\section{Three potential routes}

The question on what speciality might apply to community mediation also points to this divergence in thinking and to the implications for future route options. One route might be that community mediation practice is limited to a speciality type such as 'neighbour' relationships. Another route might be that community mediators opt for any one or a combination of the existing speciality types. As in all of the speciality types, the assumption is that discord is based purely on the material aspects of the relationship. For example, between neighbours it could be boundaries, vegetation, pets or leisure activities. This is an interesting assumption when viewed through the lens of community mediation in that it makes two suggestions which are contrary to its philosophy. Firstly, that the nature of any discord in a neighbour relationship is essentially predictable. Secondly, that mediators can strengthen their potency through the acquisition of specialist knowledge or content expertise associated with those material aspects e.g., existing legislative or formal processes.

If a mediator holds substantive knowledge or content expertise relative to the dispute, how far can they delve into the substance of the dispute without becoming totally immersed in the substance and joining with the disputants in owning the content? Being drawn into the substance of a dispute is, arguably, an occupational hazard for any mediator. Like any hazard, the associated risks need to be controlled rather than intensified. Without any control measure in place, a likely consequence is that mediators (consciously or unconsciously) lose themselves in the content. As well as being an obvious erosion of traditional core values inherent in community mediation, it gives a whole new meaning to the term 'substance abuse' - a comical or tragic connotation depending upon which way it is viewed!

While the routes discussed above offer a very different destiny for community mediation to that envisioned by community activists in 70s USA, a third route offers a continuation of the community mediation journey where its philosophical foundation is truly honoured in practice. In other words, the true potency of the community mediator lies in the practical application of recognised essential core values. Such practice allows disputants to gain courage, self-belief, strength and confidence to explore and navigate their own way through their dispute.

The essential core values of collective deliberation, self-determination, empowerment and consensus are the cornerstones of the philosophical foundation of community mediation (Beer \& Steif, 1997). These values are formulated as process skills based particularly, but not only, on the development of self and other awareness. Morin \& Everett (1990:339) point to the significance of self-awareness when they quote from Fenigstein et al (1975):

"some people constantly think about themselves, scrutinize their behaviour, and mull over their thoughts-to the point of obsessiveness. At the other extreme are persons whose absence of self- 
consciousness is so complete that they have no understanding of either their own motives or of how they appear to others".

They also conclude that self-awareness leads to self-regulation and that desirable behaviour can only emerge when a character is no longer oblivious to their undesirable behaviour.

For community mediators, this means at the very least being consciously aware that their personal motivations to mediate align with the philosophical foundation of the community mediation movement. Although there is some discourse in the literature on motivations to become a mediator, it is beyond the scope of this article to discuss the conclusions and findings (Bush \& Folger, 2005; MenkelMeadow, 1995; Benjamin, 1990). However, it is worth noting that the findings do tie motivations to individual interpretations on the concept of conflict and on the nature of third party intervention.

So the question for community mediators is whether they are motivated by the idea of regulating the behaviour of disputants or increasing their levels of self-awareness as a means of self-regulation. The latter aligns with the philosophical foundation of the community mediation movement.

\section{Conclusion}

In conclusion, the current trajectory of the Irish mediation movement, with its emphasis on specialities and associated legislative/formal processes, is not in keeping with the historic ideals of community mediation. As long as the prime focus of mediation thinkers and practitioners continues to be on content expertise at the expense of process, then the true potential of the mediation method may never be realised. Recognition of self and other awareness as a key process skill is at the core of this true potential. Such clarity and insight serves as a foundation for building understanding and human connection and, ultimately, for restoring harmony. The practice of community mediation is based on this foundation. The following quote from Pinzon (1996:18), which includes words from the French Philosopher Michel Foucault, points to the direction that reflects the true ideals behind the practice of community mediation: "we must look beyond the limits imposed by a style of mediation focused on the search for satisfactory solutions to conflicts. People know what they do; they frequently know why they do what they do; but what they don't know is what what they do does"

Finally, in choosing a direction for community mediation practice in Ireland, the current position must first be established. While this article is exploratory in nature, further research is clearly needed on existing services. Such research would provide valuable data on the reality of the three routes discussed earlier as well as providing clarity on how the historic ideals of the community mediation movement are actually being upheld. A key indicator would be the way in which the core value of collective deliberation informs the following aspects of service delivery: 
(a) service ethos and goals (this will include governance structures, referral sources and processes, service level agreements etc.);

(b) recruitment, selection, training and retention methods for volunteer mediators (this will include motivations to act as a community mediator with specific emphasis on the educational significance of the co-working model of practice);

(c) attitudes towards conflict in general and the capacity of disputants who approach the service (this will include a focus on additional supports such as conflict coaching, counselling etc.).

Without embarking on such research, community mediation in Ireland is at risk of remaining an unknown quantity, similar to its USA counterparts. Is waiting 40 years to substantiate such a discovery a rational option? The chorus that Charkoudian \& Billick (2015:250) refer to is increasing in volume:

"The need for research on the impact of community mediation was clear in Hedeen's and Baron's 2004 articles, yet little progress has been made on this front. Jeghelian et al. (2011) join the chorus of authors reinforcing the need for research and evaluation." 


\section{References}

Aureli, F. \& De Waal, F.B.M. (2000). Natural Conflict Resolution. California: University of California Press Beer, J.E. (1986). Peacemaking in Your Neighborhood: Reflections on an Experiment in Community Mediation. Philadelphia: New Society Publishers.

Beer, J.E. \& Steif, E. (1997). The Mediator's Handbook (3rd Edition). Philadelphia:

Jossey Bass

Benjamin, R. (1990). The Physics of Mediation: Reflections of Scientific Theory in Professional Mediation Practice. Mediation Quarterly, 8(2), p91-113

Bush, R.A. \& Folger, J.P. (2005). The Promise of Mediation, The Transformative Approach to Conflict, Revised Edition. San Francisco: Jossey-Bass

Charcoudian, L. \& Billick, M. (2015). State of Knowledge: Community Mediation at a Crossroads. Conflict Resolution Quarterly, 32(3), p233-276

Coy, P.G. \& Hedeen, T. (2005). A Stage Model of Social Movement Co-optation: Community Mediation in the United States. The Sociological Quarterly, 46(3), p405-435

Folberg, J. \& Taylor, A. (1984). A Comprehensive Guide to Resolving Conflicts without Litigation. San Francisco: Jossey Bass

Gazley, B., Chang, W.K \& Bingham, L.B. (2010). Board Diversity, Stakeholder Representation and Collaborative Performance in Community Mediation Centers. Public Administration Review, 70, p601-620 Hanaway, M. (Ed.). (2012). Co-Mediation: A Psychological Paired Approach to Resolving Conflict. London: Harmony Publications

Hayes, P. (2006). Two Mediate or Not Two Mediate. Masters Thesis. Unpublished.

Harrington, C.B. \& Merry, S.E. (1988). Ideological Production. The Making of

Community Mediation. Law \& Society Review, 12(4), p709-736

Herrman, M.S., Hollett, N., Eaker, D.G., Gale, J. \& Foster, M. (2002). Supporting Accountability in the Field of Mediation. Negotiation Journal, 18(1), p29-49

Menkel-Meadow, C. (1995). The Many Ways of Mediation: The Transformation of Traditions, Ideologies, Paradigms and Practices. Negotiation Journal, 11(3), p217-242

Moore, C.W. (1996). The Mediation Process, Practical Strategies For Managing Conflict. San Franciso: Jossey-

Bass Inc.

Morrill, M. \& McKee, C. (1993). Institutional Isomorphism and Informal Social Control: Evidence from a Community Mediation Center. Social Problems, 40(4), p445-463

Morin, A. \& Everett, J. (1990). Inner Speech as a Mediator of Self-Awareness, Self- Consciousness and Self-Knowledge: An Hypothesis. New Ideas in Psychology, 8(3), p337-356

Pinzon, L.A. (1996). The Production of Power and Knowledge in Mediation. Mediation Quarterly, 14(2), p3-20

Susskind, L.E. (2000). Confessions of a Public Dispute Mediator. Negotiation Journal, 16(2), p129-132 
Strasser, F. \& Randolph, P. (2004). Mediation, A Psychological Insight Into Conflict Resolution. Continuum Books: London

http://www.mediate.com - Accessed 12.30pm Wednesday 8 November 2017

http://www.themiii.ie/\#sthash.fTMs6mY8.dpbs - Accessed 12.30pm Wednesday 8 November 2017

Tricia Hayes holds a BSc (Hons) in Psychology from the University of Teesside and a Postgraduate Certificate in Education (PGCE) from the University of Huddersfield. In 2006 she completed her masters in Mediation and Conflict Resolution in University College Dublin. In 2012, she was one of a number of UK and Irish authors who contributed towards the publication of a book on Co-mediation, entitled 'Comediation: Using a psychological paired approach to resolving conflict'.

Tricia began her mediation practice as a volunteer mediator in the mid-1990s in one of the largest community-based mediation services in the UK. Her mentoring role in mediation began in the late $90 \mathrm{~s}$ and she currently provides support to mediator mentors in a Dublin-based community mediation service. She also currently supports a rural-based mediation service in their delivery of a prison-based mediation initiative. She began her teaching practice in Mediation in 1998 in the UK where she trained and assessed Mediators to Open College Network (OCN) Level 3 Standard. In 2006 she worked with the National College of Ireland (NCI) to develop a FETAC Level 6 Award in Mediation Skills and Practice. As a current Member of the Associate Faculty of the Edward M Kennedy Institute for Conflict Intervention at Maynooth University, Tricia occasionally lectures on their Masters and Diploma programmes in mediation and conflict resolution. 